\title{
Editorial
}

\section{Global Management Paradigm}

The contours of a new, global management paradigm are emerging on a worldwide basis, driven by global competition and communications, crossing the national and cultural boundaries, breaking up the old traditions, forming the new ones.

Individual components of the GMP have been coming forth steadily during the last decade, in different countries, different corporations and under different conditions. Only in recent years they have started to come together, vigorously integrated by a small but fast growing subset of world-class corporations, forming a new management system.

Management system is not just a collection of techniques, methods and approaches, but a coherent complex of interdependent practices in the spheres of organization, management, decision making and motivation.

It is also important to make a distinction between temporary management focus, strategy or technique and a management system. With the former, one can strive to refocus, improve or re-direct within any given management system, without changing it fundamentally. But a new management system is brought about not by the continuous improvement of the old but by the changing external conditions and forces, making the new natural, spontaneous and inevitable.

\section{Historical Stages}

After World War II, the traditional paradigm of product-oriented mass production (linear assembly lines, hierarchies of command, product quality

\section{IOS Press}

Human Systems Management 14 (1995) 191-194 control, and mass consumption) had reached its peak in the USA of the fifties and sixties.

Then the Deming-Juran quality focus (TQM) propelled Japan directly to the post-war process orientation (process quality control, JIT, continuous improvement), while the US had to undergo a painful and prolonged product-to-process transformation in order to level the playing field by the early nineties.

During the eighties, the building blocks of the global management paradigm (GMP) started to emerge in a variety of countries, mostly within the Pacific Rim, but in the nineties even more vigorously in the USA, through so-called process reengineering. By the mid nineties, the shape of GMP could be identified.

Short and concise characteristics of the four stages can be outlined as follows:

1. Product orientation. Final product is primary, production process secondary. Both operations and processes are fixed, but there is some sequential product variability and product quality is 'inspected in' at the end of the process. Statistical quality control, inventory control, cost minimization, mass production assembly lines, work specialization, hierarchies of command, mass consumption and reliance on statistical 'markets' are also characteristic of the era.

2. Process-operations orientation. High-quality process assures high-quality products, but not vice versa. This fundamental insight and realization brought the process forth into primary focus. The orientation still remained focused mainly on its operations. Quality of the process was understood as the quality of its operations. Concepts of Total Quality Management, Continuous Improvement (Kaizen) and Just-In-Time characterized this stage. Typically, the hierarchy is preserved, process 
structure remains intact and given and the top management still remains the main change agent.

3. Integrated-process orientation. The emphasis shifts from operations towards the 'linkages', i.e., towards the process architecture itself. The reengineering of the process, re-integrating its components into larger, autonomous and self-manageable wholes, has become the new focus. Discontinuous improvement, not just improving the operations of a fixed process, but re-integrating (reengineering and reinventing) the process itself, is the main concern of the 1990s. Through the fundamental process reengineering, the traditional hierarchies of command have started to crumble.

4. Final paradigm shift. All the previous stages have prepared the grounds for a new corporate paradigm emergence in the late 1990s: the entrepreneurial company of autonomous agents operating in an environment of intracompany markets. Not only the process, but also the very form of corporate management and governance are being 'reengineered'. The issues of motivation, ownership, entrepreneurship and creativity/innovation come to the forefront in order to assure competitiveness, learning, renewal and ecological soundness.

The above four stages characterize the post-war transition from the command hierarchy, massproduction based management/organizational paradigm to its very opposite or even negation: Global Management Paradigm (GMP). From economies of scale, through economies of scope, to the economies of integration, GMP is a natural and spontaneous order emerging from the temporary chaos and flux of searching for the new paradigm.

\section{Major Dimensions of GMP}

The newly emerging paradigm of GMP is bound to be globally dominant and widespread, at least among the actively competitive, industrialized and increasingly knowledge-based economies. Cheaplabor economies, unfortunately, remain dependent on hierarchical command. Overall, national and cultural differences increasingly constitute only a thin overlay and 'coloring' of the style, but do not affect the foundations of GMP. Global competition and its intensification requires not only the same ballgame, but also the same ballpark.

It is becoming virtually impossible for worldclass companies to continue competing while preserving, enhancing or even improving the traditional management paradigm of mass-production assembly, both in manufacturing and services. Because the new paradigm is so clearly superior, it must be adopted by any serious contenders or participants in global competition. Working harder or working smarter within the confines of the given, traditional system is not sufficient any longer.

\section{Global Management Paradigm}

1. The horizontal corporation

2. Reengineering of the process

3. Mass customization

4. Autonomous teams or cells

5. Customer integration

6. Intracompany market

7. Supplier integration

8. Elimination of tradeoffs

9. Open-book management

One can see clearly that GMP is a far cry from a 'Fourteen Points' kind of management which tries to improve, but also preserves and fixates the existing structures. TQM, Kaizen, JIT, Downsizing, Lean Production, Division of Labor, etc., are clearly missing from the list of characteristics of GMP. Although they remain important techniques and focuses, they are no longer constitutive, but implied by the more fundamental dimensions of GMP.

Let us take a closer look at the individual components of GMP:

1. The horizontal corporation. The layers of the command hierarchy are disappearing, vertical pyramids of functional organization are flattening out and horizontally organized corporation is emerging. The process or portfolio of processes represent the organizational focus, not the divisions, functions, departments or staff specialists and experts. The transitional hybrids, combining the best of both paradigms, are temporarily effective and even necessary, but the trend is inescapably accelerating towards uncompromised and undiluted horizontal corporation. 
2. Reengineering of the process. Production and service-delivery processes are being reengineered in the sense of reintegration. The essence of reengineering has very little to do with being fundamental, radical or dramatic; it has everything to do with reintegrating the process: its tasks, labor and knowledge. Tasks, operations, functions, responsibilities and skills are combined and unified into larger coherent wholes. That in itself is the major cause of the flattening of the hierarchies, not the artificial and politically motivated downsizing, 'cutting the fat' or debureaucratization.

3. Mass customization. Instead of statistically defined and behaved 'mass markets', each individual customer or group of customers have now become the market. 'Markets do not buy anything, individuals do', captures the shift quite succinctly. Individually customized products, customer-controlled completion of the production and servicedelivery process, self-service and do-it-yourself all such phenomena represent not only a change in the strategic focus, but a fundamental restructuring of the traditional ends and means of production. New technological platforms support the newly found economies of scope.

4. Autonomous teams or cells. Horizontal organizations of reintegrated processes represent networks of interacting teams, cells or amoebas: highly integrated, small teams of employees who own (not just 'as if') the production process. Process ownership, responsibility, creativity and selfmanagement are the main characteristics of teams. Teams can be closer to the customer, can masscustomize, respond flexibly and behave responsibly. They assure higher productivity and quality while allowing the cost to decrease.

5. Customer integration. Customer has become a part of the production process, purpose of the enterprise, driving force of the strategy and the final arbiter of product and service quality, variety and cost. Customers provide crucial input into product design, production scheduling and post-purchase maintenance, recovery and recycling. Customer has become major corporate stakeholder and investor and customer satisfaction has become primary measure of corporate performance.

6. Intracompany market. Autonomous teams in a horizontal corporation are organized, coordinated and synchronized with the help of internal market economy. This is based on external market prices, free contractual agents, internal competition and continuous formation, re-formation and dissolution of teams and networks of teams in order to fit the business environment and circumstances most effectively. Corporate boundaries become semipermeable to physical and information fluctuations. The external suppliers and customers are drawn into direct interaction with corporate internal customers.

7. Supplier integration. Also known as Co-location, it reaches well beyond the Lean Production and JIT by bringing the suppliers directly and physically within and inside the production or assembly plant. Supplier Integration also differs from classical vertical integration in that the colocated suppliers are physically integrated, but remain autonomous and independent in terms of management and performance.

8. Elimination of tradeoffs. Also known as Tradeoffs-Free Management, the elimination of tradeoffs allows the improvement in quality, cost, flexibility, productivity and timeliness - all at the same time. The portfolio of corporate resources and its optimization (or optimal design) is the key towards tradeoffs elimination. Managing any given system optimally is fundamentally different from and vastly inferior to managing an optimally designed system.

9. Open-book management. Corporate information is not a secret or privilege, but an increasingly important management tool. All employees must know not only what to do and when, but mainly why. Information has to be shared, propagated and broadcast throughout the company: only then can employees share directly in the company's success or failure. Employees cease being hired hands and start thinking like owners - by becoming equity owners, a basis for all long-term thinking.

Not many world-class companies have been able to institute the GMP as a whole system. More typically, different companies have implemented different components or subsets of components of GMP separately and independently. To realize that the GMP components are interdependent and mutually enhancing and amplifying requires systems 
thinking which is not typically a part of current executives' education and experience.

Clearly, reengineering and horizontal corporation are intimately related, as are customer and supplier integration. Co-location cannot function properly within a traditional hierarchy and intracompany markets are actually incompatible with it. Autonomous teams and cells are the prerequisite for intracompany markets and for mass customization, which cannot function properly without customer integration. Open information sharing is a prerequisite for any serious free-market functioning, anywhere.

\section{Early Practitioners of GMP}

Among the early, albeit still partial practitioners of GMP we find a variety of international companies. Kyocera Corp. of Kyoto is world famous for its intracompany markets (The 'Amoeba' system) which made it the most successful company of Japan.

Experiments with intracompany markets are also going on at Alcoa, Clark Equipment, Esso Petroleum Canada and Control Data, among others.

Skoda (VW of Bohemia) is one of the early practitioners of Supplier Integration with several suppliers fully co-located. New Fiat plant at Malfi (Italy) plans full co-location of more than 60 percent of its suppliers.

Compaq Computer Corp. has been most innovative in scrapping its traditional (and successful) assembly lines and replacing them with three-person cells or teams, producing to customer orders and stopping expensive reliance on traditional forecasting.

Levi Strauss has become one of the largest mass customizers, providing its customers with over 4,200 fitting options of blue jeans. Mass customization has really taken over in the USA (because of the excellent overnight private mail and delivery infrastructure) and one can point to Gateway 2000, Motorola, Andersen Windows and Hallmark Cards as being among the pioneers.

Consequently, self-service, do-it-yourself, workat-home and all forms of teleworking and telecommuting are also booming: they either provide or support mass customization on a large scale.

The Horizontal or Team-Based Organization is taking hold at Xerox, XMark International, AT\&T, Motorola, etc., with Eastman Kodak, 3M, DuPont and Asea Brown Boveri not too far behind.

\section{Conclusions}

Although GMP seems to be evolving most rapidly in the USA, some good or even pioneering examples can be drawn also from Japan, Italy, Germany, Korea and even Bohemia. In other words, GMP does not have a clear national or cultural focus, but represents a new management/organizational paradigm of a global, world-wide nature and scope.

The introduced dimensions of GMP could be still too few or too many - it is still too early to predict with full confidence. Some dimensions will be fused together, some others will be added or dropped over time. However, in its broad outlines, this is what the new management paradigm contours are and they are unlikely to change fundamentally. They will be further refined, tuned up and specified, new support technologies will be developed and the experience will sharpen new tools and new skills. Consumers and customers will change their behavior and preferences accordingly, together with the producers of goods and services.

The differences between producers and consumers will ultimately disappear and Toffler's 'prosumers' will become an integral part of new economic reality. The differences between production (and products) and services are already disappearing quite rapidly: producers offer fundamental services and services market new and innovative products. The term 'service industry' captures it all.

It is time to stop wasting time with the fads and fashions of disconnected parts and concentrate on the emerging whole - the system.

$$
\begin{array}{r}
\text { Milan ZELENY } \\
\text { Graduate School of Business } \\
\text { Fordham University at Lincoln Center } \\
\text { New York, NY 10023 } \\
\text { USA }
\end{array}
$$

